Research Article

\title{
Electrochemical Generation of Hydrogen and Methanol using ITO Sheet Decorated with Modified-Titania as Electrode
}

\author{
Tariq Abbas, Muhammad Tahir*, Nor Aishah Saidina Amin \\ Chemical Reaction Engineering Group, School of Chemical and Energy Engineering, Universiti \\ Teknologi Malaysia (UTM), 81310 Johor Bahru, Johor, Malaysia.
}

Received: $3^{\text {rd }}$ March 2021; Revised: 30th April 2021; Accepted: $5^{\text {th }}$ May 2021

Available online: $6^{\text {th }}$ May 2021; Published regularly: June 2021

\section{Abstract}

Current issues of global warming and environmental pollution due to extensive use of fossil fuels has been reached to an alarming position. Being $\mathrm{CO}_{2}$ as main byproduct of fossil fuel consumption and water as abundantly available on earth surface has great potential to replace fossil fuels as energy source. Herein, electrocatalytic $\mathrm{CO}_{2}$ reduction with water for methanol and hydrogen gas $\left(\mathrm{H}_{2}\right)$ production over ITO sheet decorated with modified-Titanium nanorods $\left(\mathrm{TiO}_{2} \mathrm{NR}\right)$, has been investigated. The performance comparison of electrocatalytic activity of hydrothermally modified-titania with commercial $\mathrm{TiO}_{2}$ microparticles (MP) were further investigated. Electrochemical reactor containing $\mathrm{KHCO}_{3}$ aqueous solution with $\mathrm{CO}_{2}$ as an electrolyte and modified $\mathrm{TiO}_{2}$ nanorods (NR) as working electrodes offer an eco-friendly system to produce clean and sustainable energy system. The typical rates of product, i.e. methanol and $\mathrm{H}_{2}$ generation from the ITO sheet decorated with modified $\mathrm{TiO}_{2} \mathrm{NR}_{\text {layer recorded higher }}$ than those for the ITO sheet with commercial $\mathrm{TiO}_{2}$ microparticle. At $2.0 \mathrm{~V}$ applied potential vs $\mathrm{Ag} / \mathrm{AgCl}$ as reference electrode, the modified $\mathrm{TiO}_{2} \mathrm{NR}$ electrocatalyst yielded methanol at a rate of $3.32 \mu \mathrm{mol} . \mathrm{cm}^{-2} \cdot \mathrm{L}^{-1}$ and $\mathrm{H}_{2}$ at a rate of $6 \mu \mathrm{mol} . \mathrm{cm}^{-2} . \mathrm{L}^{-1}$ which was higher than that of commercial $\mathrm{TiO}_{2} \mathrm{MP}$ electrocatalyst (methanol $=1.5$ $\mu \mathrm{mol} . \mathrm{cm}^{-2} . \mathrm{L}^{-1}$ and $\left.\mathrm{H}_{2}=3.7 \mu \mathrm{mol} . \mathrm{cm}^{-2} . \mathrm{L}^{-1}\right)$. The enhancement in product yields of methanol and $\mathrm{H}_{2}$ was mainly due to the notable improvements and modification in texture of $\mathrm{TiO}_{2}$ working electrode interface. Hence, it is concluded that the modified $\mathrm{TiO}_{2} \mathrm{NR}$ can be considered as a competent candidate for sustainable energy conversion applications.

Copyright (C 2021 by Authors, Published by BCREC Group. This is an open access article under the CC BY-SA License (https://creativecommons.org/licenses/by-sa/4.0).

Keywords: $\mathrm{CO}_{2}$ electroreduction; water electrocatalysis; methanol; hydrogen; $\mathrm{TiO}_{2}$ nanorods

How to Cite: T. Abbas, M. Tahir, N.A.S. Amin (2021). Electrochemical Generation of Hydrogen and Methanol using ITO Sheet Decorated with Modified-Titania as Electrode. Bulletin of Chemical Reaction Engineering \& Catalysis, 16(2), 430-439 (doi:10.9767/bcrec.16.2.10514.430-439)

Permalink/DOI: https://doi.org/10.9767/bcrec.16.2.10514.430-439

\section{Introduction}

Currently, the earth's main energy sources are mostly depending on non-renewable fossil fuels such as petroleum oils, coal and natural

\footnotetext{
* Corresponding Author.

Email:mtahir@cheme.utm.my; bttahir@yahoo.com (M. Tahir); Tel: +60146281678
}

gas [1-2]. These sources of energy are limited in nature, and their utilization and consumption process cause environmental pollution due to the emission of greenhouse gases $\left(\mathrm{CO}_{2}\right)$ and air pollution ( $\mathrm{SOx}$ and $\mathrm{NOx}$ ), all of these problems lead to global warming and serious climatic changes [3-4]. A cleaner production of hydrogen $\left(\mathrm{H}_{2}\right)$ has a great potential to substitute fossil fuel utilization due to its immense advantages, such as higher energy density and zero carbon 
footprint up on use. Presently, most of the $\mathrm{H}_{2}$ production is commercially done by steam reforming of natural gas, which causes $\mathrm{CO}_{2}$ emissions [5]. Electrochemical (EC) process can be used to produce $\mathrm{H}_{2}$ via electrocatalysis of water under low electrical bias. The $\mathrm{CO}_{2}$ produced as byproduct of steam reforming of natural gas and utilization of other fossil fuels can also be converted back to methanol using EC process. The electrocatalytic efficiency of $\mathrm{CO}_{2}$ reduction and direct water electrocatalysis depends on the working electrode or semiconductor used as electrocatalyst.

In recent years, numerous semiconductor materials, such as: $\mathrm{SnO}_{2}, \mathrm{InP}, \mathrm{CdS}, \mathrm{g}-\mathrm{C}_{3} \mathrm{~N}_{4}$, $\mathrm{Bi}_{2} \mathrm{WO}_{6}, \mathrm{Cu}_{2} \mathrm{O}, \mathrm{InSe}_{2}, \mathrm{BiVO}_{4}, \mathrm{PbO}_{2}, \mathrm{rGO}, \mathrm{CeO}_{2}$ and $\mathrm{TiO}_{2}$ [6-12], have been investigated as electrocatalysts in EC system for $\mathrm{CO}_{2}$ and reduction $\mathrm{H}_{2}$ evolution reaction. However, $\mathrm{TiO}_{2}$ has been considered as a standard benchmark for researchers after the pioneering research work conducted by Fujishima and Honda for electrocatalytic process [13,14]. High demand for $\mathrm{TiO}_{2}$ as electrocatalyst is due to high stability in a corrosive environment, facile in preparation and structure modification, abundant availability, economical in cost and ecofriendly $[15,16]$. In EC applications, $\mathrm{TiO}_{2}$ has been extensively investigated for both $\mathrm{CO}_{2}$ reduction and water oxidation for methanol and $\mathrm{H}_{2}$ evolution reactions $[9,17,18]$. Particularly, $\mathrm{TiO}_{2}$ is considered as one of the promising electrocatalyst and semiconductor for EC processes because of its easy availability, cheap, negative flat band potential, unique electronic configuration, stable towards corrosive chemicals and ecofriendly. However, commercially available $\mathrm{TiO}_{2}$ microparticle suffers from rapid recombination of charge, lower product selectivity, larger bandgap $(\sim 3.2 \mathrm{eV})$, and less catalytic efficiency [19]. This is due to the lower surface area and fast electrons $\left(\mathrm{e}^{-}\right)$and holes $\left(\mathrm{h}^{+}\right)$recombination rates which effects the efficiency of electrocatalytic activity methanol and $\mathrm{H}_{2}$ production [20]. Both properties of $\mathrm{TiO}_{2}$ affect the efficiency of catalytic activity in methanol and $\mathrm{H}_{2}$ production [21].

The efficiency of $\mathrm{TiO}_{2}$ can be improved by surface modification and changing the structure of $\mathrm{TiO}_{2}$ crystals. $\mathrm{TiO}_{2}$ exists in various structural phases such as brookite, rutile and anatase [22]. The anatase phase of $\mathrm{TiO}_{2}$ is considered most efficient in electrocatalytic processes as compared to brookite and rutile phase. Moreover, the catalytic efficiency highly relies on the crystal structures of $\mathrm{TiO}_{2}$ which exist in various forms, such as: microparticles, nanoparticles, and nanorods. High catalytic activity could be obtained with nanorods structures due to higher active sites or surface area compared to the microparticles and nanoparticles [23]. The structural morphologies can be controlled based on the synthesize method of $\mathrm{TiO}_{2}$. The problem of charge recombination and surface area can be addressed by changing and modification of surface morphology of $\mathrm{TiO}_{2}$ for better charge transfer and enhanced surface area [24,25]. Based on these assumptions and viewpoints, herein, we aimed to synthesize simple and uniquely modified $\mathrm{TiO}_{2}$ nanorods electrocatalyst for efficient $\mathrm{CO}_{2}$ reduction and direct electrocatalysis of water to produce methanol and $\mathrm{H}_{2}$.

In this study, we synthesis the $\mathrm{TiO}_{2}$ nanorods via hydrothermal method using sodium hydroxide as alkaline agent. The as prepared $\mathrm{TiO}_{2}$ nanorod (NR) sample was used to fabricate electrode for electrocatalytic $\mathrm{CO}_{2}$ reduction into methanol and $\mathrm{H}_{2}$ production by using catalyst ink method. Commercial $\mathrm{TiO}_{2}$ microparticles (MP) were also used in the electrode fabrication for comparison purpose. The synthesized $\mathrm{TiO}_{2} \mathrm{NR}$ and commercial $\mathrm{TiO}_{2} \mathrm{MP}$ were characterized to analyze the structural phase and surface morphology by using X-ray Diffraction (XRD), Brunauer-Emmett-Teller (BET), Field Emission Scanning Electron Microscope (FESEM), and High-resolution transmission electron microscopy (HR-TEM) techniques. Both $\mathrm{TiO}_{2} \mathrm{NR}$ and commercial $\mathrm{TiO}_{2} \mathrm{MP}$ electrodes were subjected to electrocatalytic $\mathrm{CO}_{2}$ reduction for the electrocatalytic performance evaluation on the basis of methanol and $\mathrm{H}_{2}$ production.

\section{Materials and Methods}

\subsection{Materials}

Titanium(IV) oxide $\left(\mathrm{TiO}_{2}\right)$, anatase (99.9\%), Sodium hydroxide $(\mathrm{NaOH})(97.0 \%)$ and Dimethylsulfoxide (DMSO) (99.5\%) were analytical grade reagents and used without further purification. Indium tin oxide coated glass slide (ITO), surface resistivity 15-25 $\mathrm{\Omega} / \mathrm{sq}$, Platinum $(\mathrm{Pt})$ wire (purity = 99.9\%), Ag/AgCl (3.5 M KCl) reference electrode and all other chemical were purchased from Sigma-Aldrich Sdn Bhd, Malaysia. Carbon dioxide $\left(\mathrm{CO}_{2}\right)$ gas (purity = 99.9\%), Hydrogen $\left(\mathrm{H}_{2}\right)$ gas (purity $=99.9 \%$ ) and all other gases required for gas chromatograph (GC) system were acquired from Mega Mount Industrial Gases Sdn. Bhd., Malaysia. Deionized water was used as solvent for all aqueous solutions. 


\subsection{Synthesis of Electrocatalyst}

$\mathrm{TiO}_{2} \mathrm{NR}$ synthesized by using hydrothermal method, reported elsewhere [26]. In this method $1.5 \mathrm{~g}$ of $\mathrm{TiO}_{2}$ (anatase) powder was added to $70 \mathrm{~mL}$ of $\mathrm{NaOH}(10 \mathrm{M})$ aqueous solution After stirring for $1 \mathrm{~h}$, the solution was transferred to a $100 \mathrm{~mL}$ autoclave and heated at $200^{\circ} \mathrm{C}$ for 24 h. The precipitate was centrifuged and washed with deionized water and ethanol several times until the $\mathrm{pH}$ value reached $\sim 7$. The wet product was kept in an oven for drying at $100{ }^{\circ} \mathrm{C}$ for 12 $\mathrm{h}$. The obtained sample was crushed and calcined in a furnace at $500{ }^{\circ} \mathrm{C}$ for $5 \mathrm{~h}$. The synthesized sample is denoted by $\mathrm{TiO}_{2} \mathrm{NR}$ afterwards.

\subsection{Synthesis of Electrode}

Modified $\mathrm{TiO}_{2} \mathrm{NR}$ electrode was fabricated on ITO slide by using catalyst ink method. For this purpose, $0.1 \mathrm{~g}$ of $\mathrm{TiO}_{2} \mathrm{NR}$ was mixed in 10 $\mu \mathrm{L}$ DMSO and sonicated for $6 \mathrm{~h}$ to synthesis evenly dispersed and viscus catalyst ink. After preparation of catalyst ink, the ITO slide was carefully covered with catalyst ink by drop casting method. The ITO slide covered with catalyst ink was then transferred to oven for drying at $100^{\circ} \mathrm{C}$ for $6 \mathrm{~h}$.

\subsection{Catalyst Characterizations}

The structure and degree of crystallinity were carried out using XRD technique. The XRD patterns were obtained by the D5000 Siemens instrument using $\mathrm{Cu}-\mathrm{k} \alpha$ radiation (40 kev. $40 \mathrm{~mA}$ ). The patterns were evaluated at a scanning rate of $1.2^{\circ} \cdot \mathrm{min}^{-1}$ and a scanning range of $10-90^{\circ}$ of $2 \theta$. The diffractometer is armed with a Ni-filtered $\mathrm{Cu} \mathrm{K} \alpha$ radiation source $(\lambda=1.54056 \AA)$. The X-ray source was operated at $40 \mathrm{kV}$ and $200 \mathrm{~mA}$. The phase identification of the as-prepared sample was analyzed by comparison to Joint Committee on Powder Diffraction Standards (JCPDS). The morphology of the electrodes and catalyst powder was analyzed by field emission scanning electron microscopy (FESEM) by using Hitachi SU8020. The high-resolution transmission electron microscope (HR-TEM) images of the as-prepared electrocatalyst samples was obtained from the JEOL JEM-ARM 200F HRTEM transmission electron microscope. Electrochemical characterizations such as cyclic voltammetry (CV) was performed by using an electrochemical workstation (Keithley-2450EC, Tektronix, USA). In a typical threeelectrode system with $0.1 \mathrm{M} \mathrm{KHCO}_{3}$ as electrolyte in a homemade EC microreactor $\left(100 \mathrm{~cm}^{3}\right)$

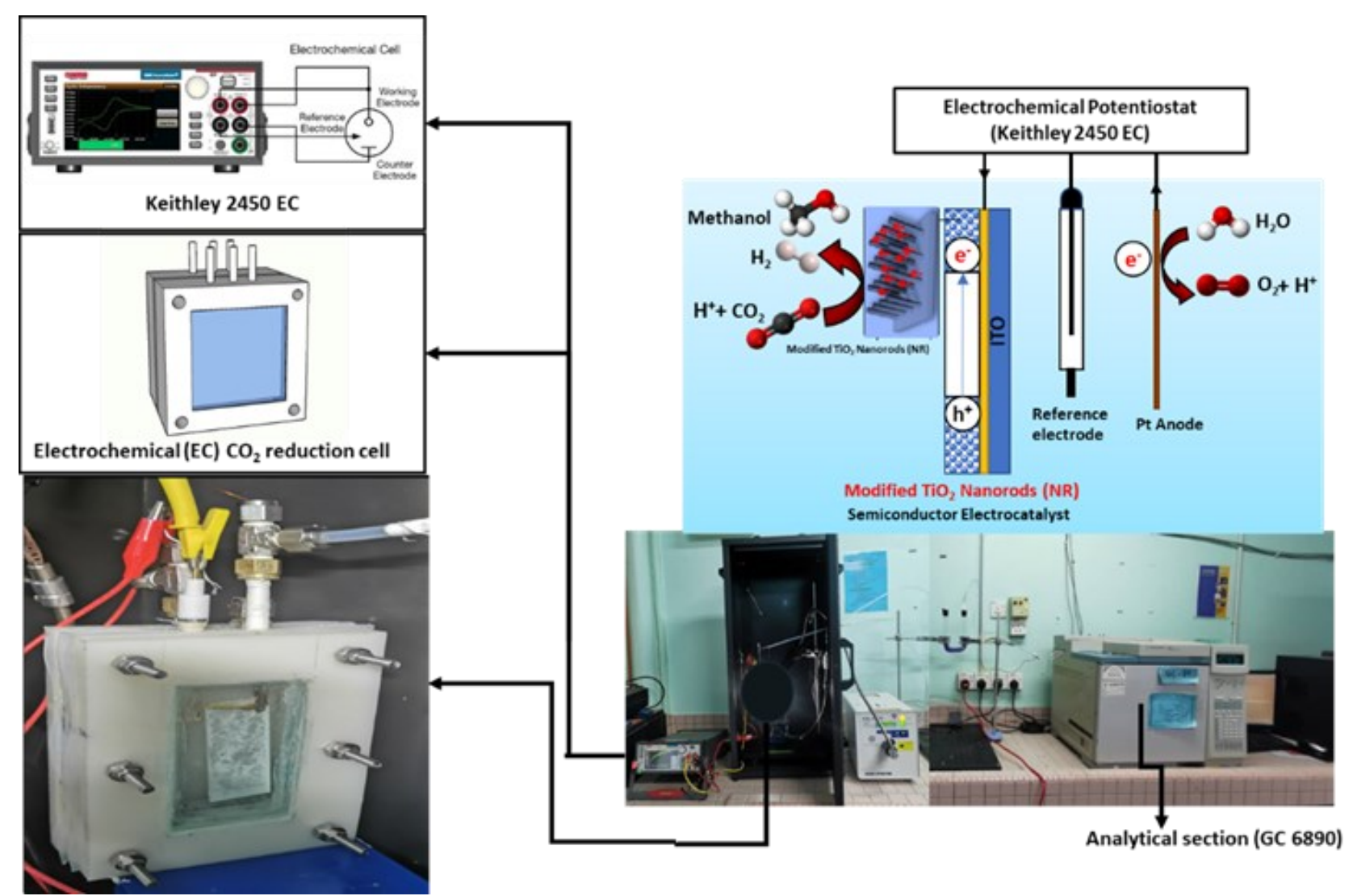

Figure 1. Electrochemical (EC) experimental setup with schematic diagram of the process. 
with continuous flow/bubbling of $\mathrm{CO}_{2}$ at 20 $\mathrm{m} / \mathrm{min}$. The prepared electrocatalyst samples, platinum plate and standard $\mathrm{Ag} / \mathrm{AgCl}$ electrode were used as working, counter and reference electrode, respectively.

\subsection{Experimental Setup and Reactor Configura-} tion

The schematic of experimental setup for the homemade electrocatalytic (EC) reactor system is presented in Figure 1 . The $\mathrm{KHCO}_{3}(0.1 \mathrm{M})$ as

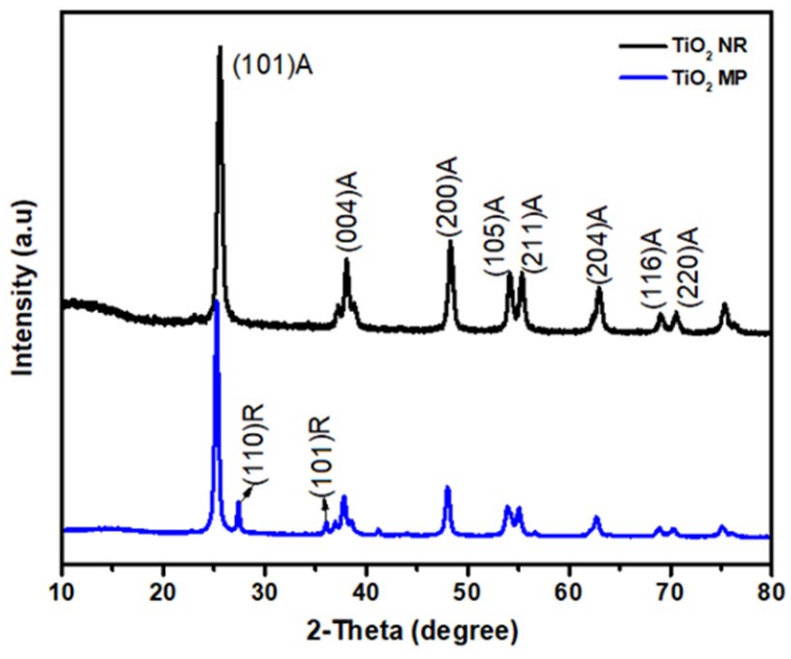

Figure 2. XRD pattern of $\mathrm{TiO}_{2}$ nanorods (NR) and microparticle (MP) catalyst samples. ${ }^{*} \mathrm{~A}=$ anatase and $\mathrm{R}=$ Rutile. electrolyte for the EC reaction system is fed into the EC reactor cell. Then, the $\mathrm{CO}_{2}$ is introduced into EC reactor cell by a digital mass flow controller (Alicat Scientific Mc-1Slpm-D $\left.\left(\mathrm{CO}_{2}\right)\right)$ at a flow rate of $20 \mathrm{~mL} / \mathrm{min}$. The potential difference across EC reactor cell was applied by an electrochemical workstation (Keithley-2450-EC, Tektronix, USA) in a typical three-electrode system. The prepared electrocatalyst samples coated on ITO slide, platinum plate and standard $\mathrm{Ag} / \mathrm{AgCl}$ electrode is used as working, counter and a reference electrode, respectively. To analyze the electrocatalysis for $\mathrm{H}_{2}$ production and $\mathrm{CO}_{2}$ reduction for methanol production under light irradiation, a solar simulator model number LAX-C100, Asahi Spectra was used as light source. The gas products were analyzed through an online gas chromatograph (GC) system (model No: Agilent $6890 \mathrm{~N}$ ) connected with a thermal conductivity detector (TCD) and Carbon-PLOT capillary column $(0.53 \mathrm{~mm} \times 30 \mathrm{~m})$. The temperature of the $\mathrm{GC}$ system column was set at $200{ }^{\circ} \mathrm{C}$. The liquid product was analyzed through an offline gas chromatograph (GC) system (model No: Agilent $7820 \mathrm{~N}$ ) connected with a Flame-ionization detection (FID) and a DB-WAX capillary column $(0.25 \mathrm{~mm} \times 30 \mathrm{~m})$. The performance of the EC reactor system using different catalysts are reported and analyzed by Equations (1) and (2) product yield $\left(\mu \mathrm{mol} . \mathrm{cm}^{-2} \cdot \mathrm{L}^{-1}\right)$ and Faradaic efficiency (\%), respectively.
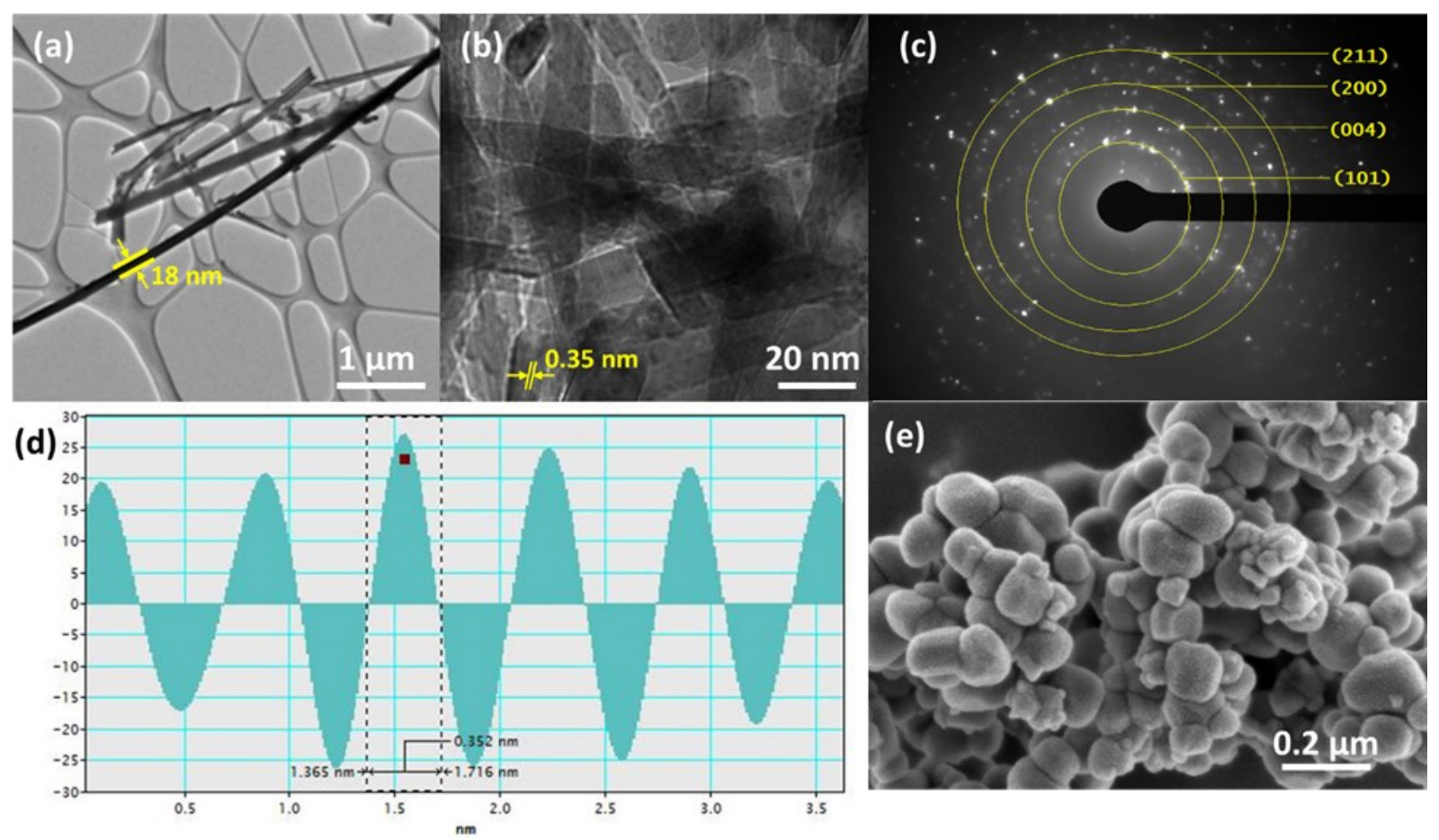

Figure 3. (a-b) HR-TEM micrographs of $\mathrm{TiO}_{2}$ nanorods (NR), (c) SAED pattern of $\mathrm{TiO}_{2} \mathrm{NR}$, (d) observed d-spacing value for $\mathrm{TiO}_{2} \mathrm{NR}$ and (e) FESEM of $\mathrm{TiO}_{2}$ microparticle (MP) electrocatalyst. 
Product Yield $=\frac{\text { moles of Product }}{\text { Electrode area } \times \text { Volume of reactor }}$

Faradaic Efficiency $(F E)=\frac{\varepsilon \times n \times F}{Q} \times 100$

\section{Results and Discussion}

\subsection{Characterization of Electrocatalysts}

The X-ray diffraction patterns of $\mathrm{TiO}_{2} \mathrm{NR}$ and $\mathrm{TiO}_{2} \mathrm{MP}$ electrocatalyst samples, calcined at $500{ }^{\circ} \mathrm{C}$ up to $5 \mathrm{~h}$ are shown in Figure 2. The peaks for $\mathrm{TiO}_{2} \mathrm{NR}$ and MP were indicated at 2 theta (degree) $25.4^{\circ}, 38.0^{\circ}, 48.1^{\circ}, 53.0^{\circ}, 55.2^{\circ}$ and $62.9^{\circ}$, which corresponds to (101), (004), (200), (105), (211) and (204) planes associated with tetragonal anatase, all in pure anatase phase. However, in $\mathrm{TiO}_{2} \mathrm{MP}$ diffraction patterns additional peaks at $27.4^{\circ}$ and $36.07^{\circ}$ can be seen, which corresponds to (110) and (101) planes associated with rutile phase [27]. Similar XRD peaks were reported by Steky et al. [28] for the nanostructured titania via alkaline hydrothermal treatment using ammonia solution with the presence of anatase and trace of rutile phases. It can be concluded that the $\mathrm{TiO}_{2}$ NR structure in pure anatase phase can be acquired via hydrothermal method using $\mathrm{NaOH}$ as alkaline agent.

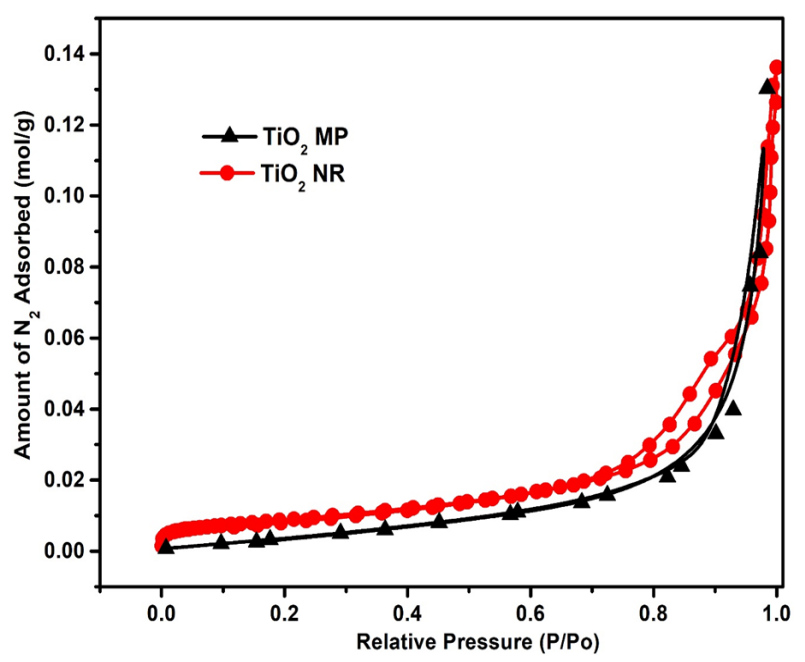

Figure 4. $\mathrm{N}_{2}$ adsorption-desorption isotherms of $\mathrm{TiO}_{2} \mathrm{NR}$ and $\mathrm{TiO}_{2} \mathrm{MP}$ electrocatalyst.
HR-TEM micrographs and FESEM of $\mathrm{TiO}_{2}$ nanorods (NR) and $\mathrm{TiO}_{2}$ microparticle (MP) electrocatalysts are depicted in Figure 3a-e. In Figure 3a, the HR-TEM micrographs of $\mathrm{TiO}_{2}$ nanorods (NR) shows the formation of nanorod structures with approximately 6-8 micrometers in length and $18 \mathrm{~nm}$ in diameter. Figure $3 \mathrm{~b}$ shows d-spacing of $0.35 \mathrm{~nm}$ which corresponds to the (101) facet of $\mathrm{TiO}_{2}$ anatase phase. The value of $d$-spacing was observed by using DigitalMicrograph ${ }^{\circ}$, Gatan Inc. software tool, as shown in Figure 3d. From the SAED patterns as depicted in Figure 3c, the crystal interplanar spacings corresponding to diffraction rings/facets starting from inner side to outwards were (101), (112), (211), and (220). The FESEM micrograph of $\mathrm{TiO}_{2}$ microparticle is also depicted in Figure 3e, where we can observe the $\mathrm{TiO}_{2}$ particles are in micro-spherical form. However, HR-TEM micrographs confirms the formation of $\mathrm{TiO}_{2}$ nanorod structure of hydrothermally synthesized electrocatalyst.

The $\mathrm{N}_{2}$ adsorption and desorption isotherms of the calcined $\mathrm{TiO}_{2} \mathrm{NR}$ and $\mathrm{TiO}_{2} \mathrm{MP}$ are shown in Figure 4. Both microparticle and nanorods show increase in $\mathrm{N}_{2}$ absorption above 0.9 partial pressure $\left(\mathrm{P} / \mathrm{P}_{0}\right)$. Furthermore, $\mathrm{N}_{2}$ adsorption-desorption isotherms revealed mesoporous structure for $\mathrm{TiO}_{2} \mathrm{NR}$ with hysteresis

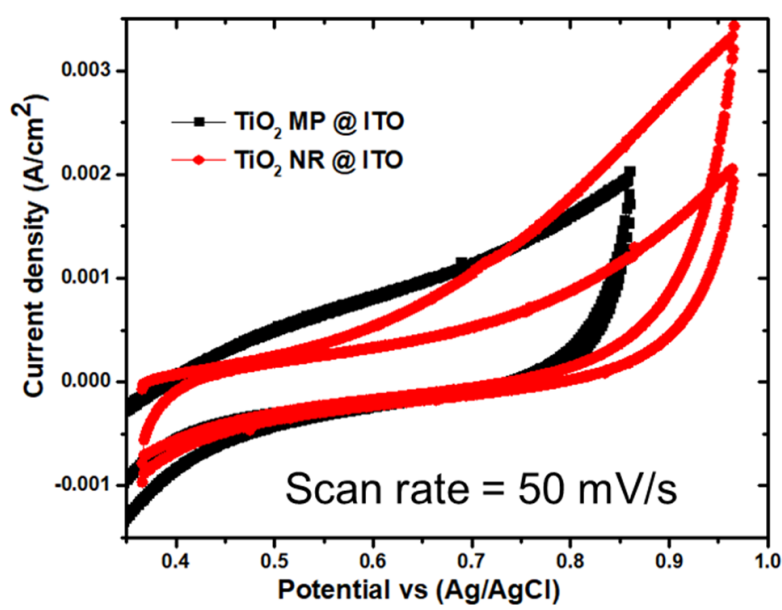

Figure 5. Cyclic voltammetry curves for various electrodes/electrocatalyst @.50 mV/s and 0.3 to $1.0 \mathrm{~V}$ vs $\mathrm{Ag} / \mathrm{AgCl}$ potential range.

Table 1. Summary of structural properties $\mathrm{TiO}_{2} \mathrm{NR}$ and $\mathrm{TiO}_{2} \mathrm{MP}$ electrocatalyst samples.

\begin{tabular}{cccc}
\hline Catalyst & $\begin{array}{c}\text { BETSA } \\
\left(\mathrm{m}^{2} / \mathrm{g}\right)\end{array}$ & $\begin{array}{c}\text { Pore radius } \\
(\mathrm{nm})\end{array}$ & $\begin{array}{c}\text { Pore volume } \\
\left(\mathrm{cm}^{3 / \mathrm{g}}\right)\end{array}$ \\
\hline $\mathrm{TiO}_{2} \mathrm{MP}$ & 25.43 & 9.70 & 0.15 \\
$\mathrm{TiO}_{2} \mathrm{NR}$ & 50.26 & 12.72 & 0.31 \\
\hline
\end{tabular}

${ }^{*} \mathrm{SA}=$ Surface Area 
loop of type IV according to IUPAC. The summary of structural properties including BET surface area, pore volume and pore size/radius of $\mathrm{TiO}_{2} \mathrm{MP}$ and $\mathrm{TiO}$ NR are presented in Table 1. The BET surface area of $\mathrm{TiO}_{2} \mathrm{MP}$ was 25.43 $\mathrm{m}^{2} / \mathrm{g}$, pore volume $0.15 \mathrm{~cm}^{3} / \mathrm{g}$ and pore radius $9.70 \mathrm{~nm}$ were recorded. However, BET surface area of hydrothermally modified $\mathrm{TiO}_{2} \mathrm{NR}$ was recorded as $50.62 \mathrm{~m}^{2} / \mathrm{g}$ which is higher than unmodified commercial $\mathrm{TiO}_{2} \mathrm{MP}$ catalyst sample. Similar trends were observed in the pore volume $0.31 \mathrm{~cm}^{3} / \mathrm{g}$ and pore radius $12.72 \mathrm{~nm}$ of $\mathrm{TiO}_{2} \mathrm{NR}$, which were recorded higher as compared to $\mathrm{TiO}_{2} \mathrm{MP}$. The significant increments in structural properties of modified $\mathrm{TiO}_{2} \mathrm{NR}$ was obtained through simple hydrothermal treatment and these structural properties of $\mathrm{TiO}_{2} \mathrm{NR}$ might enhance the electrocatalytic performance.

The measurement of cyclic voltammetry (CV) curve at $50 \mathrm{mV} / \mathrm{s}$ scan rate within a potential range $\sim 0.3$ to $1.0 \mathrm{~V}$ vs $\mathrm{Ag} / \mathrm{AgCl}$ was per-

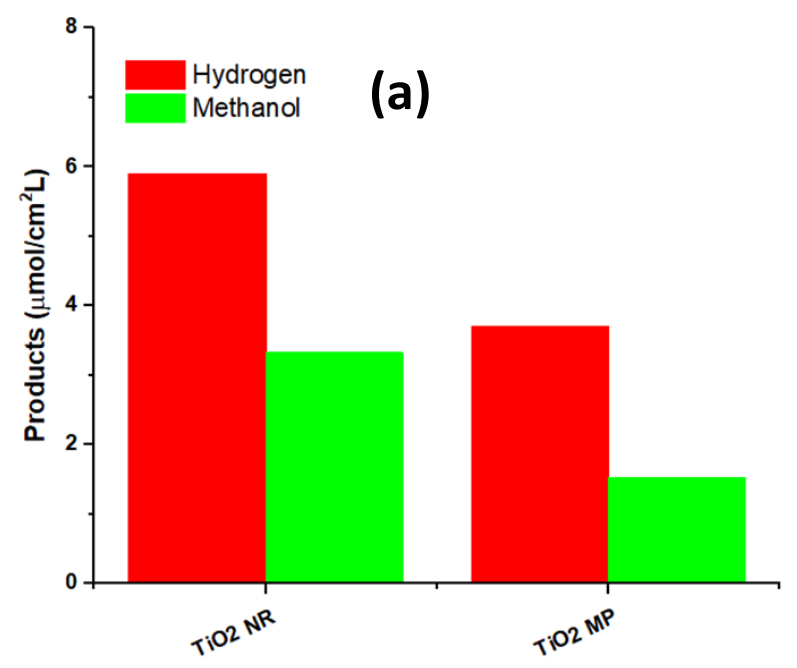

(b)

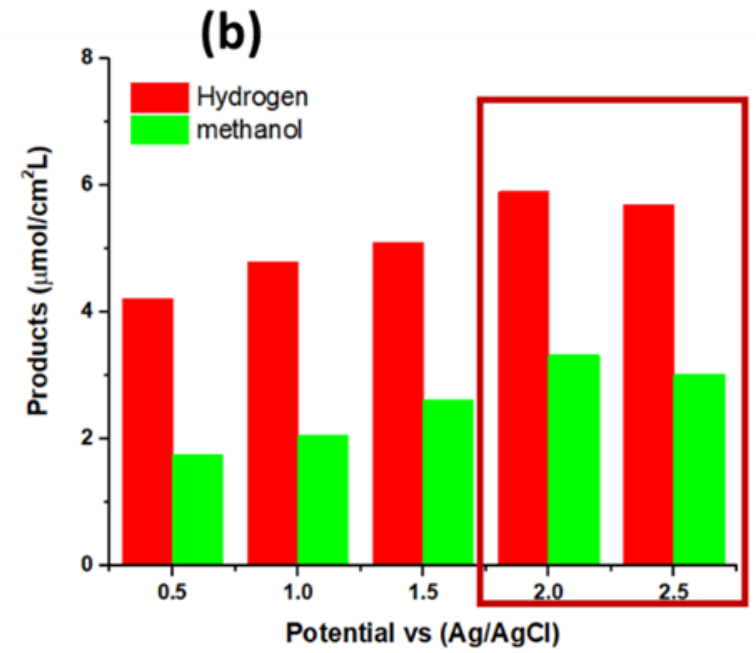

formed for different samples and depicted in Figure 5. The CV tests shows relatively higher electrochemical surface area and current density for $\mathrm{TiO}_{2} \mathrm{NR}$ electrocatalyst as compared to other samples. This increment is desirable for enhanced electrocatalytic activity towards $\mathrm{CO}_{2}$ reduction for methanol and direct water electrolysis for $\mathrm{H}_{2}$ production. It can be observed from the cyclic voltammetry curves the current density of $\mathrm{TiO}_{2} \mathrm{NR}$ increases with the increase in the applied potential. It shows that with increase in the applied potential the current density increases, which results in the enhanced electrocatalytic reactions for methanol formation and $\mathrm{H}_{2}$ production at electrodeelectrolyte interface. The present cyclic voltammetry data is consistent with reported literature for electrocatalytic activity for $\mathrm{CO}_{2}$ reduction [21].

\subsection{Electrocatalytic $\mathrm{CO}_{2}$ Reduction}

To analyze the direct water electrocatalysis for $\mathrm{H}_{2}$ production and $\mathrm{CO}_{2}$ reduction for methanol production under $2 \mathrm{~V}$ of applied potential using three electrode system. An online gas chromatography (GC-TCD, Agilent 6890) equipped with Carbon plot column was used to analyze the gas products and an offline liquid GC-FID (Agilent, 7820A) equipped with DBWAX column was used to analyze liquid products. In outlet product gas mainly $\mathrm{H}_{2}$ was observed and in the liquid methanol was detected. Figure $6 \mathrm{a}$ shows the electrocatalytic activity test for different electrodes. As we can observe from the experiments that $\mathrm{TiO}_{2} \mathrm{NR}$ electrocatalyst showed highest catalytic activity in terms of $\mathrm{H}_{2}$ and methanol production. The $\mathrm{H}_{2}$ and methanol production rate for modified

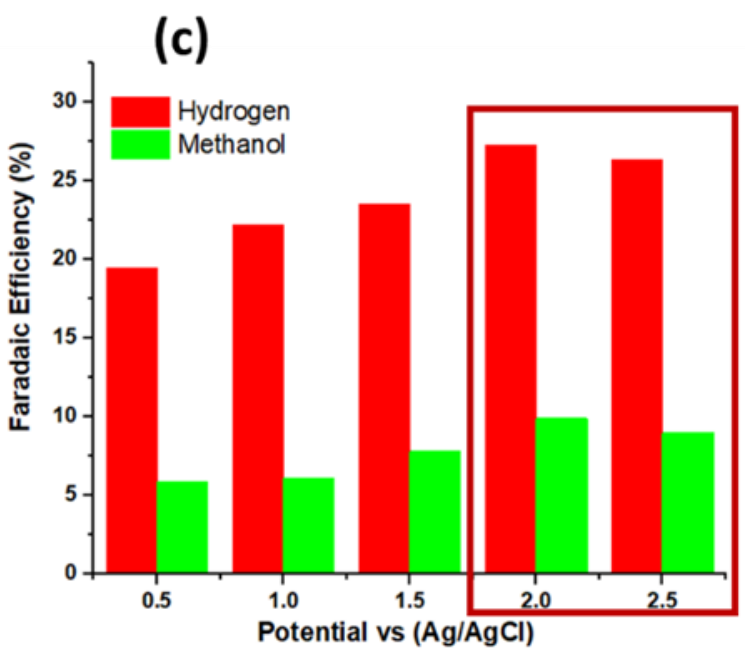

Figure 6. (a) Electrocatalytic activity test for different electrocatalysts (b-c) electrocatalytic activity of $\mathrm{TiO}_{2}$ NR electrocatalyst under different electric potentials. 
$\mathrm{TiO}_{2} \mathrm{NR}$ electrocatalyst at $2 \mathrm{~V}$ of potential vs $\mathrm{Ag} / \mathrm{AgCl}$ for $1 \mathrm{~h}$ was recorded as $\sim 6.0$ $\mu \mathrm{mol} . \mathrm{cm}^{-2} . \mathrm{L}^{-1}$ and $3.32 \mu \mathrm{mol} . \mathrm{cm}^{-2} . \mathrm{L}^{-1}$, respectively. The electrocatalytic activity of $\mathrm{TiO}_{2} \mathrm{NR}$ electrocatalyst was further investigated under different applied electric potentials $(0.5-2.5 \mathrm{~V})$, as depicted in Figure 6b and 6c. As shown in the results, product yield and faradaic efficiency for methanol and $\mathrm{H}_{2}$ production increased gradually from $0.5 \mathrm{~V}$ to $2.0 \mathrm{~V}$ applied potentials. However, a slight decline in methanol and $\mathrm{H}_{2}$ production rate and faradaic efficiency can be absorbed at $2.5 \mathrm{~V}$ applied potential. The decline in product generation and faradaic efficiency might be due to overpotential that causes excess concentration of $\mathrm{H}^{+} / \mathrm{or}^{\mathrm{OH}^{-}}$species around electrodes. These excess $\mathrm{H}^{+} / \mathrm{or} \mathrm{OH}^{-}$species causes hindrance for $\mathrm{CO}_{2}$ adsorption on catalyst surface that results in decline in production rate and faradaic efficiency. Huang et al. [29] also reported similar trend for product generation in electrocatalytic $\mathrm{CO}_{2}$ reduction to methanol.

The improvement in product yields of methanol and $\mathrm{H}_{2}$ was mainly due to the notable improvements and modification in morphology of
$\mathrm{TiO}_{2}$ electrocatalyst interface. Moreover, the improvements in catalytic activity of $\mathrm{TiO}_{2} \mathrm{NR}$ electrocatalyst might be due to enhanced charge separation for $\mathrm{TiO}_{2}$ after surface modification. The cyclic voltammetry (CV) results for $\mathrm{TiO}_{2}$ NR electrocatalyst also provide justification for the enhanced catalytic activity.

\subsection{Electrocatalytic Mechanism of $\mathrm{CO}_{2}$ Reduc- tion}

On the basis of available related literature and experiments, we propose a hypothetical reaction mechanism for electrocatalytic $\mathrm{CO}_{2}$ reduction to methanol and $\mathrm{H}_{2}$ over $\mathrm{TiO}_{2} \mathrm{NR}$ electrocatalyst. The schematics of proposed reaction mechanism is shown in Figure 7. In the first step, the oxidation of electrolyte/water containing $\mathrm{OH}^{-}$occurs at anode side. After losing electron to anode proton $/ \mathrm{H}^{+}$produced at anode side and due to concentration gradient, these protons $/ \mathrm{H}^{+}$migrate towards cathode side. At cathode side, after bubbling and dissolving $\mathrm{CO}_{2}$ through electrolyte, molecules of dissolved $\mathrm{CO}_{2}$ start to adsorb at electrocatalyst by creating a complex $\left[\mathrm{TiO}_{2} \mathrm{NR}-\mathrm{CO}_{2}\right]^{+}$via interaction of

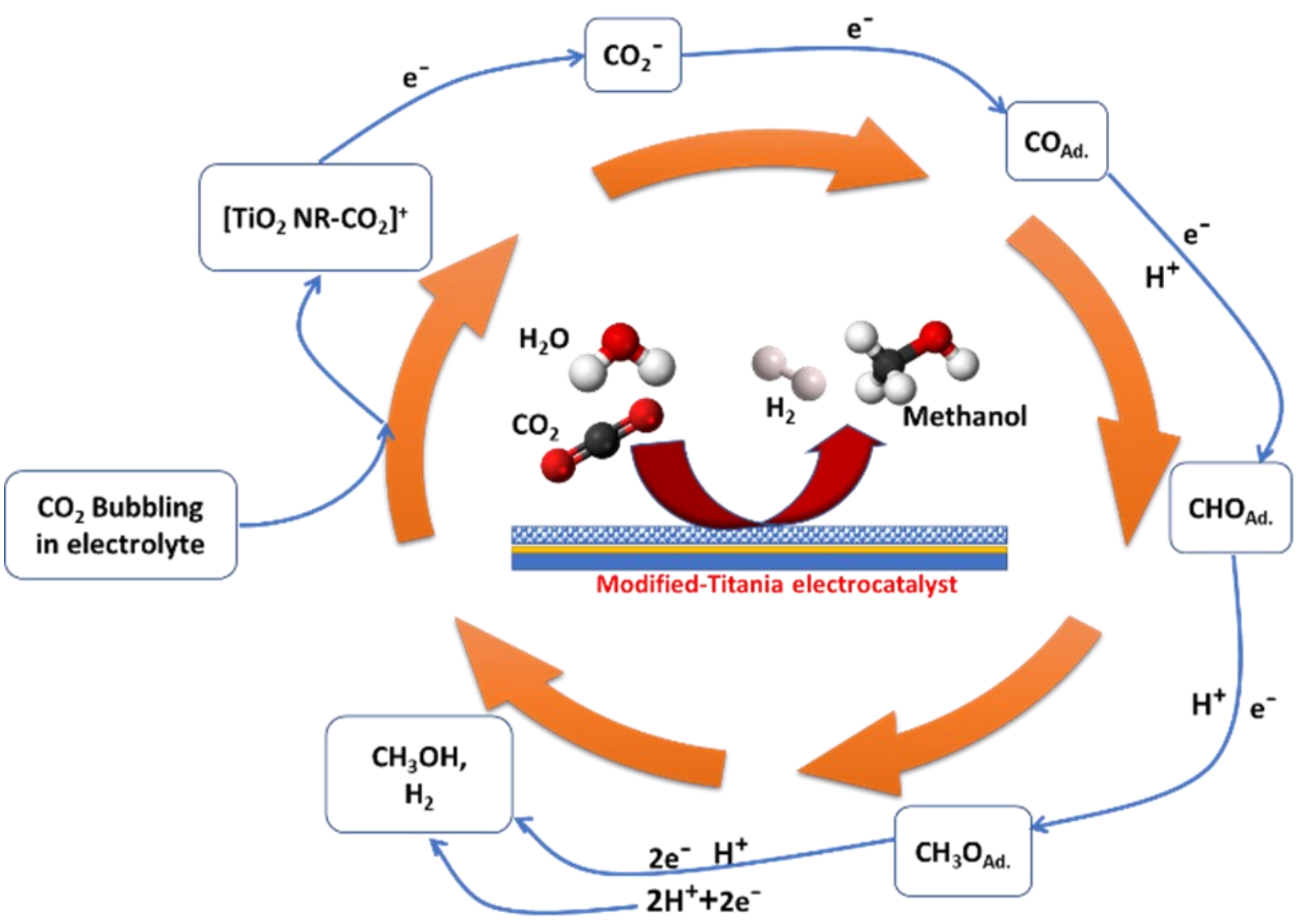

Figure 7. Schematic reaction mechanism for electrocatalytic $\mathrm{CO}_{2}$ reduction over $\mathrm{TiO}_{2} \mathrm{NR}$. 
hydrogen between molecules. After adsorption of $\mathrm{CO}_{2}$ complex on electrocatalyst, the $\mathrm{CO}_{2}$ molecule convert into $\mathrm{CO}_{2}{ }^{-}$after reduction process. The reduced $\mathrm{CO}_{2}^{-}$molecule further transfer second electron to convert into intermediate $\mathrm{CO}$ or adsorbed $\mathrm{CO} / \mathrm{CO}_{\mathrm{Ad}}$. After that, third transfer of electron occurs along with proton $/ \mathrm{H}^{+}$to convert $\mathrm{CO}_{\text {Ad. }}$ into adsorbed $\mathrm{CHO}$ or $\mathrm{CHO}_{\text {Ad. }}$ intermediate. Further, electron and proton $/ \mathrm{H}^{+}$transfer leads to conversion of $\mathrm{CHO}_{\mathrm{Ad}}$. into intermediate $\mathrm{CH}_{3} \mathrm{O}$ or adsorbed $\mathrm{CH}_{3} \mathrm{O}_{\text {Ad. }}$. intermediate. In final step, the last electron and proton $/ \mathrm{H}^{+}$is transferred to the $\mathrm{CH}_{3} \mathrm{O}_{\text {Ad. }}$ and methanol is produced at electrocatalyst. Also, two protons $/ \mathrm{H}^{+}$ react with two electrons to produce 1 mole of hydrogen. The overall reaction is shown in Equations (3) and (4).

$$
\begin{gathered}
\mathrm{CO}_{2}+6 \mathrm{H}^{+}+6 e^{-} \rightarrow \mathrm{CH}_{3} \mathrm{OH}+\mathrm{H}_{2} \mathrm{O} \\
E^{o}=-0.38 \mathrm{~V} \text { vs SHE }(p H=7) \\
2 \mathrm{H}^{+}+2 e^{-} \rightarrow \mathrm{H}_{2} \\
E^{o}=-0.41 \mathrm{~V} \text { vs } \mathrm{SHE}(\mathrm{pH}=7)
\end{gathered}
$$

\section{Conclusions}

The synthesized ITO sheet decorated with $\mathrm{TiO}_{2}$ NR electrocatalyst can efficiently boost charge separation and surface area to improve the methanol and $\mathrm{H}_{2}$ production rates for $\mathrm{CO}_{2}$ reduction and direct water electrocatalysis during the EC reaction. The $\mathrm{TiO}_{2} \mathrm{NR}$ electrocatalyst catalysts exhibit excellent $\mathrm{EC} \mathrm{CO}_{2}$ reduction and water electrolysis activity with methanol production value of $3.32 \mu \mathrm{mol} . \mathrm{cm}^{-2} . \mathrm{L}^{-1}$ and $\mathrm{H}_{2}$ production value of $6 \mu \mathrm{mol} . \mathrm{cm}^{-2} \cdot \mathrm{L}^{-1}$ under $2.0 \mathrm{~V}$ of applied electric potential. The CV experiments for $\mathrm{TiO}_{2} \mathrm{NR}$ electrocatalyst also confirms the justification for the improved catalytic performance. This work develops an effective and facile $\mathrm{TiO}_{2} \mathrm{NR}$ electrocatalyst as a competent EC working electrode for sustainable energy conversion.

\section{Acknowledgments}

The authors would like to thank Universiti Teknologi Malaysia (UTM) and Ministry of Higher Education (MoHE), Malaysia for funding this research under FRGS Grant Vot. No. $5 \mathrm{~F} 101$.

\section{References}

[1] Zhu, J., Hu, L., Zhao, P., Lee, L.Y.S., Wong, K.Y. (2020). Recent Advances in Electrocatalytic Hydrogen Evolution using Nanoparticles. Chemical Reviews, 120, 851-918. DOI: 10.1021/acs.chemrev.9b00248.
[2] Tahir, B., Er, P.W., Tahir, M., Nawawi, M.G.M., Siraj, M., Alias, H., Fatehmulla, A. (2020). Tailoring metal/support interaction in $0 \mathrm{D} \mathrm{TiO}_{2} \mathrm{NPs} / \mathrm{MPs}$ embedded 2D MAX composite with boosted interfacial charge carrier separation for stimulating photocatalytic $\mathrm{H}_{2}$ production. Journal of Environmental Chemical Engineering, 8(6), 104529. DOI: 10.1016/j.jece.2020.104529

[3] Zhang, W., Hu, Y., Ma, L., Zhu, G., Wang, Y., Xue, X., Chen, R., Yang, S., Jin, Z. (2018). Progress and Perspective of Electrocatalytic $\mathrm{CO}_{2}$ Reduction for Renewable Carbonaceous Fuels and Chemicals. Advanced Science, 5, 1700275. DOI: 10.1002/advs.201700275.

[4] Abbas, T., Tahir, M. (2021). Tri-metallic NiCo modified reducible $\mathrm{TiO}_{2}$ nanocomposite for boosting $\mathrm{H} 2$ production through steam reforming of phenol. International Journal of Hydrogen Energy, 46(13), 8932-8949. DOI: 10.1016/j.ijhydene.2020.12.209

[5] Song, R.-B., Zhu, W., Fu, J., Chen, Y., Liu, L., Zhang, J.-R., Lin, Y., Zhu, J.-J. (2020). Electrode Materials Engineering in Electrocatalytic $\mathrm{CO}_{2}$ Reduction: Energy Input and Conversion Efficiency. Advanced Materials, 32, 1903796. DOI: 10.1002/adma.201903796.

[6] Yang, P., Li, W., Lian, Y., Yu, F., Dai, B., Guo, X., Liu, Z., Peng, B. (2020). A Facile Approach to Synthesize $\mathrm{CoO}-\mathrm{Co}_{3} \mathrm{O}_{4} / \mathrm{TiO}_{2} \mathrm{NAs}$ for Reinforced Photoelectrocatalytic Water Oxidation. Journal of Solid State Electrochemistry, 24, 941-950. DOI: 10.1007/s10008-02004528-y

[7] Jiang, X.X., De Hu, X., Tarek, M., Saravanan, P., Alqadhi, R., Chin, S.Y., Rahman Khan, M.M. (2020). Tailoring the Properties of g$\mathrm{C}_{3} \mathrm{~N}_{4}$ with $\mathrm{CuO}$ for Enhanced Photoelectrocatalytic $\mathrm{CO}_{2}$ Reduction to Methanol. Journal of $\mathrm{CO}_{2}$ Utilization, 40, 101222. DOI: 10.1016/j.jcou.2020.101222.

[8] Tahir, M., Tahir, B., Nawawi, M.G.M., Hussain, M., Muhammad, A. (2019). Cu-NPs Embedded 1D/2D CNTs/pCN Heterojunction Composite Towards Enhanced and Continuous Photocatalytic $\mathrm{CO}_{2}$ Reduction to Fuels. Applied Surface Science, 485, 450-461. DOI: 10.1016/j.apsusc.2019.04.220

[9] Perini, J.A.L., Torquato, L.D.M., Irikura, K., Zanoni, M.V.B. (2019). Ag/PolydopamineModified $\mathrm{Ti} / \mathrm{TiO}_{2}$ Nanotube Arrays: A Platform for Enhanced $\mathrm{CO}_{2}$ Photoelectroreduction to Methanol. Journal of $\mathrm{CO}_{2}$ Utilization, 34, 596-605. DOI: 10.1016/j.jcou.2019.08.006.

[10] Marino, T., Figoli, A., Molino, A., Argurio, P., Molinari, R. (2019). Hydrogen and Oxygen Evolution in a Membrane Photoreactor using Suspended Nanosized $\mathrm{Au} / \mathrm{TiO}_{2}$ and $\mathrm{Au} / \mathrm{CeO}_{2}$. ChemEngineering, 3, 5. DOI: 10.3390/chemengineering3010005. 
[11] Li, D., Wang, S., Tian, Y., Ma, H.P., Ma, C., Fu, Y., Dong, X. (2018). Preparation and Photoelectrocatalytic Performance of $\mathrm{Ti} / \mathrm{PbO}_{2}$ Electrodes Modified with $\mathrm{Ti}_{4} \mathrm{O}_{7}$. Chemistryselect, 3, 5098-5105. DOI: 10.1002/slct.201703181.

[12] Tahir, M. (2019). La-modified $\mathrm{TiO}_{2} /$ Carbon Nanotubes Assembly Nanocomposite for Efficient Photocatalytic Hydrogen Evolution from Glycerol-Water Mixture. International Journal of Hydrogen Energy, 44(7), 3711-3725. DOI: 10.1016/j.ijhydene.2018.12.095

[13] Inoue, T., Fujishima, A., Konishi, S., Honda, K. (1979). Photoelectrocatalytic Reduction of Carbon Dioxide in Aqueous Suspensions of Semiconductor Powders. Nature, 277, 637638. DOI: $10.1038 / 277637 a 0$

[14] Fujishima, A., Honda, K. (1972). Electrochemical Photolysis of Water at a Semiconductor Electrode. Nature, 238, 37-38. DOI: $10.1038 / 238037 \mathrm{a} 0$

[15] Nasralla, N., Yeganeh, M., Astuti, Y., Piticharoenphun, S., Shahtahmasebi, N., Kompany, A., Karimipour, M., Mendis, B.G., Poolton, N.R.J., Šiller, L. (2013). Structural and Spectroscopic Study of Fe-doped $\mathrm{TiO}_{2} \mathrm{Na}$ noparticles Prepared by Sol-Gel Method. Scientia Iranica, 20(3), 1018-1022. DOI: 10.1016/j.scient.2013.05.017

[16] Nasralla, N.H.S., Yeganeh, M., Astuti, Y., Piticharoenphun, S., and Šiller, L. (2018). Systematic Study of Electronic Properties of Fe-doped $\mathrm{TiO}_{2}$ Nanoparticles by X-ray Photoemission Spectroscopy. Journal of Materials Science: Materials in Electronics, 29(20), 17956-17966. DOI: 10.1007/s10854-018-99115

[17] Zhu, S., Chen, X., Li, Z., Ye, X., Liu, Y., Chen, Y., Yang, L., Chen, M., Zhang, D., Li, G., Li, H. (2020). Cooperation between Inside and Outside of $\mathrm{TiO}_{2}$ : Lattice $\mathrm{Cu}^{+}$Accelerates Carrier Migration to the Surface of Metal Copper for Photocatalytic $\mathrm{CO}_{2}$ Reduction. Applied $\mathrm{Ca}$ talysis B: Environmental, 264, 118515. DOI: 10.1016/j.apcatb.2019.118515.

[18] Sheu, J.K., Liao, P.H., Lee, Y.C., Wang, H.K., Lee, M.L. (2020). Photoelectrochemical Generation of Hydrogen and Formic Acid using GaN Films Decorated with $\mathrm{TiO}_{2} / \mathrm{Ag}$ Nanoparticles Composite Structure as Photoelectrodes. The Journal of Physical Chemistry C, $124, \quad 9591-9598$. D O I : 10.1021/acs.jpcc.0c01699.

[19] Liu, Z., Xu, K., Yu, H., Sun, Z. (2020). Synergistic Effect of $\mathrm{Ag} / \mathrm{MoS}_{2} / \mathrm{TiO}_{2}$ Heterostructure Arrays on Enhancement of Photoelectrochemical and Photocatalytic Performance. International Journal of Energy Research, 1-13. DOI: 10.1002/er.6275.
[20] Baran, E., Yazici, B. (2016). Effect of Different Nano-Structured $\mathrm{Ag}$ Doped $\mathrm{TiO}_{2}-\mathrm{NTs}$ Fabricated by Electrodeposition on the Electrocatalytic Hydrogen Production. International Journal of Hydrogen Energy, 41, 24982511. DOI: 10.1016/j.ijhydene.2015.12.028.

[21] Zhou, J., Li, Y., Yu, L., Li, Z., Xie, D., Zhao, Y., Yu, Y. (2020). Facile in Situ Fabrication of $\mathrm{Cu}_{2} \mathrm{O} @ \mathrm{Cu}$ Metal-Semiconductor Heterostructured Nanorods for Efficient Visible-Light Driven $\mathrm{CO}_{2}$ Reduction. Chemical Engineering Journal, $385, \quad 123940$. DOI: 10.1016/j.cej.2019.123940.

[22] Kerdnoi, P., Autthanit, C., Chitpong, N., Jongsomjit, B. (2020). Catalytic Dehydration of Ethanol over W/TiO 2 Catalysts Having Different Phases of Titania Support. Bulletin of Chemical Reaction Engineering \& Catalysis, 15, 96-103. DOI: 10.9767/bcrec.15.1.5606.96103.

[23] Petronella, F., Diomede, S., Fanizza, E., Mascolo, G., Sibillano, T., Agostiano, A., Curri, M.L., Comparelli, R. (2013). Photodegradation of Nalidixic Acid Assisted by $\mathrm{TiO}_{2} \mathrm{Nano}-$ rods/Ag Nanoparticles based Catalyst. Chemosphere, 91(7), 941-947. DOI: 10.1016/j.chemosphere.2013.01.107

[24] Karim, K.M.R., Ong, H.R., Abdullah, H., Yousuf, A., Cheng, C.K., Khan, M.M.R. (2018). Electrochemical Study of Copper Ferrite as a Catalyst for $\mathrm{CO}_{2}$ Photoelectrochemical Reduction. Bulletin of Chemical Reaction Engineering \& Catalysis, 13, 236-244. DOI: 10.9767/bcrec.13.2.1317.236-244.

[25] Zarei, E., Jamali, M.R., Ahmadi, F. (2018). Highly Sensitive Electrocatalytic Determination of Formaldehyde using a Ni/Ionic Liquid Modified Carbon Nanotube Paste Electrode. Bulletin of Chemical Reaction Engineering \& Catalysis, 13, 529-542. DOI: 10.9767/bcrec.13.3.2341.529-542.

[26] Abbas, T., Tahir, M., Saidina Amin, N.A. (2019). Enhanced Metal-Support Interaction in $\mathrm{Ni} / \mathrm{Co}_{3} \mathrm{O}_{4} / \mathrm{TiO}_{2}$ Nanorods toward Stable and Dynamic Hydrogen Production from Phenol Steam Reforming. Industrial \& Engineering Chemistry Research, 58, 517-530. DOI: 10.1021/acs.iecr.8b03542.

[27] Lee, C.H., Rhee, S.W., Choi, H.W. (2012). Preparation of $\mathrm{TiO}_{2}$ Nanotube/Nanoparticle Composite Particles and their Applications in Dye-Sensitized Solar Cells. Nanoscale Research Letters, 7(1), 48. DOI: 10.1186/1556276X-7-48 
[28] Steky, F.V., Suendo, V., Mukti, R.R., Benu, D.P., Reza, M., Adhika, D.R., Tanuwijaya, V.V., Nugraha, A.B. (2019). bcl Morphology Formation Strategy on Nanostructured Titania via Alkaline Hydrothermal Treatment. Bulletin of Chemical Reaction Engineering \& Catalysis, 14, 513-520. DOI: 10.9767/bcrec.14.3.3853.513-520.
[29] Huang, J., Guo, X., Yue, G., Hu, Q., Wang, L. (2018). Boosting $\mathrm{CH}_{3} \mathrm{OH}$ Production in Electrocatalytic $\mathrm{CO}_{2}$ Reduction over Partially Oxidized $5 \mathrm{~nm}$ Cobalt Nanoparticles Dispersed on Single-Layer Nitrogen-Doped Graphene. ACS Applied Materials \& Interfaces, 10(51), 44403-44414. DOI: 10.1021/acsami.8b14822

Selected and Revised Papers from International Conference on Sustainable Energy and Catalysis 2021 (ICSEC 2021) (https://engineering.utm.my/chemicalenergy/icsec2021/) (School of Chemical and Energy Engineering, Faculty of Engineering, Universiti Teknologi Malaysia, 16-17th February 2021) after Peer-reviewed by Scientific Committee of ICSEC 2021 and Peer-Reviewers of Bulletin of Chemical Reaction Engineering \& Catalysis.

Editors (Guest) in this ICSEC 2021 section are Nor Aishah Saidina Amin, Mohd Asmadi Mohammed Yussuf, Salman Raza Naqui, while Editor in Chief is I. Istadi. 